\title{
The value of chest CT for prediction of breast tumor size: comparison with pathology measurement
}

Su Joa Ahn ${ }^{1+}$, Young Saing Kim ${ }^{2+}$, Eun Young Kim ${ }^{1 *}$, Heung Kyu Park ${ }^{3}$, Eun Kyung Cho ${ }^{2}$, Yoon Kyung Kim, Yon Mi Sung ${ }^{1}$ and Hye-Young Choi ${ }^{1}$

\begin{abstract}
Background: Little information is available on the use of chest computed tomography (CT) to predict breast tumor size in breast cancer, despite the fact that chest $C T$ examinations are being increasingly used. The purpose of this study was to evaluate the value of chest $\mathrm{CT}$ for predicting breast tumor size using pathology measurements as reference standards.

Methods: Tumor sizes (defined as greatest diameter) were retrospectively measured on the preoperative chest $\mathrm{CT}$ images of 285 patients with surgically proven unifocal, invasive breast carcinoma. Greatest tumor diameters as determined by chest $\mathrm{CT}$ and pathologic examinations were compared by linear regression and Spearman's rho correlation analysis. Concordance between $\mathrm{CT}$ and pathology results was defined as a diameter difference of $<5 \mathrm{~mm}$. Subgroup analyses were also performed with respect to tumor size $(<20 \mathrm{~mm}$ or $\geq 20 \mathrm{~mm})$ and histological subtype (invasive ductal carcinoma(IDC) or non-IDC).

Results: $C T$ and pathology measured diameters were found to be linearly related (size at pathology $=1.086 \times C T$ determined tumor size - 1.141; Spearman's rho correlation coefficient $=0.84, P<0.001)$. Most tumors $(n=228,80.0 \%)$ were concordant by chest $C T$ and pathology, but 36 tumors (12.7\%) were underestimated by $C T$ (average underestimation, $11 \mathrm{~mm}$; range, 6-36 mm) and 21 tumors (7.4\%) were overestimated (average overestimation by $\mathrm{CT}, 10 \mathrm{~mm}$; range, 6-19 $\mathrm{mm}$ ). The concordance rate between the two sets of measurements was greater for tumor of $<20 \mathrm{~mm}$ and for IDC $(P<0.001$ and $P=0.011$, respectively).

Conclusions: Tumor size by chest $C T$ is well correlated with pathology determined tumor size in breast cancer patients, and the diameters of the majority of tumors by chest $C T$ and pathology differed by $<5 \mathrm{~mm}$. In addition, the concordance rate was higher for breast tumors of $<20 \mathrm{~mm}$ and for tumors of the IDC histologic subtype.
\end{abstract}

Keywords: Breast cancer, Chest CT, Tumor size, Pathology

\section{Background}

Breast cancer is the most common malignancy in women, and accounts for $15 \%$ of all cancers [1]. The accurate estimation of tumor size and extent in breast cancer is essential for surgical planning and minimizing local recurrence after surgery [2,3], and recently, chest computed tomography $(\mathrm{CT})$ has been used to detect

\footnotetext{
* Correspondence: oneshot0229@gmail.com

†Equal contributors

1Department of Radiology, Gachon University GilHospital, 1198, Guwol-dong, Namdong-gu, Incheon 405-760, Republic of Korea

Full list of author information is available at the end of the article
}

pulmonary and hepatic metastasis in patients with breast cancer before surgery. However, chest CT screening is not currently recommended in operable and asymptomatic patients with breast cancer $[4,5]$, although the use of chest CT examinations in breast cancer patients is undoubtedly increasing. Furthermore, a review of the literature revealed that no study has yet addressed the use of chest CT for determining breast tumor size. Accordingly, the purpose of this study was to assess the value of chest CT for determining breast tumor size using pathology measurements as reference standards.

\section{Biomed Central}

(c) 2013 Ahn et al.; licensee BioMed Central Ltd. This is an Open Access article distributed under the terms of the Creative Commons Attribution License (http://creativecommons.org/licenses/by/2.0), which permits unrestricted use, distribution, and reproduction in any medium, provided the original work is properly cited. 
Table 1 Clinicopathologic characteristics of the study subjects

\begin{tabular}{llll}
\hline Characteristics & $\begin{array}{l}\text { Tumors }<\mathbf{2 0} \mathbf{~ m m} \\
\text { on CT }(\boldsymbol{n}=\mathbf{1 3 9})\end{array}$ & $\begin{array}{l}\text { Tumors } \geq \mathbf{2 0} \mathbf{~ m m} \\
\text { on CT }(\boldsymbol{n}=\mathbf{1 4 6})\end{array}$ & $\boldsymbol{P}$ values \\
\hline Age (years) & $50.1 \pm 9(31-78)$ & $47.5 \pm 10(20-79)$ & $0.249^{\mathrm{b}}$
\end{tabular}

Stages

IA

IB

IIB

T2

T4

N1
$\| \mathrm{A}$

IIIA

IIIB

IIIC

Tstages

$\mathrm{T} 1$

$\mathrm{T} 3$

$N$ stages

NO

N2

N3

ER status

Positive

Negative

PR status

Positive

Negative

HER-2

amplification

Positive

Negative

Unknown

Histopathologic

type

Invasive ductal

carcinoma

Invasive lobular

carcinoma

Others $^{\text {d }}$

Histologic grade

Grade 1

Grade 2

Grade 3

31

\section{9}

0

74
Table 1 Clinicopathologic characteristics of the study subjects (Continued)

\begin{tabular}{llll}
\hline Operation type & & & \\
Mastectomy & 17 & 33 & $0.051^{\mathrm{c}}$ \\
$\begin{array}{l}\text { Breast conserving } \\
\text { surgery }\end{array}$ & 122 & 113 &
\end{tabular}

a Mean values with standard deviations (numbers in parentheses are ranges).

b Two-sample t- test.

c Chi-squared test.

d Others including invasive papillary carcinoma $(n=6)$, invasive micropapillary carcinoma $(n=5)$, mucinous carcinoma $(n=4)$, metaplastic carcinoma $(n=4)$, invasive tubular carcinoma $(n=3)$, invasive apocrine carcinoma $(n=3)$, neuroendocrine carcinoma $(n=1)$, invasive carcinoma with squamous differentiation $(n=1)$.

e Scarff-Bloom-Richardson grade system.

ER, estrogen receptor; PR, progesterone receptor.

\section{Methods}

Patients

We retrospectively searched archived records in a practice specializing in breast surgery from April 2010 to January 2012 for breast cancer patients that underwent chest CT before surgical treatment. The inclusion criteria adopted were newly diagnosed, biopsy-proven, unifocal breast cancer with a positive chest CT scan. Finally, 285 patients (mean age, 48.79 years; range, 20-79 years) were included. Baseline characteristics of the study cohort are provided in Table 1.

Gross and histopathologic examinations of surgical specimens were performed by staff pathologists. Crosssections of formalin-fixed paraffin-embedded specimens were obtained at $5-\mathrm{mm}$ intervals perpendicular to the line connecting the nipple and the tumor center. Specimens were examined microscopically using hematoxylin and eosin staining. Lesion sizes were measured and largest tumor diameter was defined as tumor size.

Histopathologic diagnosis revealed invasive ductal carcinoma (IDC) in 86\%, invasive lobular carcinoma (ILC) in $4.5 \%$, invasive papillary carcinoma in $2.1 \%$, and othersin $7.4 \%$. The parameters used for multidetector computed tomography (MDCT) (Somatom Sensation 16 or 64 scanners, Siemens Medical Solutions, Forchheim, Germany) examinations were as follows: $100-120 \mathrm{kVp}$, $170 \mathrm{mAs}, 5-\mathrm{mm}$ collimation, a $10 \mathrm{~mm} / \mathrm{s}$ table feed with a 1-s rotation time, $5.0-\mathrm{mm}$ slice thickness, and 2.5-5.0 $\mathrm{mm}$ intervals. Synthetic sagittal and coronal images were reformatted at intervals of $3 \mathrm{~mm}$ and fully covered the region from anterior skin to the back of the chest. The effective dose for chest CT was $4.0 \mathrm{mSv}$, based on a standard patient model using an anthropomorphic phantom, and a conversion factor of $0.017 \mathrm{mSv} /(\mathrm{mGy} . \mathrm{cm})$ was used to convert dose-length product to effective dose [6]. Prior to chest CT, all patients fasted for $>6 \mathrm{~h}$. Iopromide $(120 \mathrm{~mL}$; Ultravist; Bayer Schering Pharma, Berlin) was injected intravenously at a rate of $4 \mathrm{~mL} / \mathrm{s}$, and CT images were obtained 30-40 s later. Our 
institutional review board approved this retrospective study, and the requirement for informed patient consent was waived.

\section{Image analysis}

A subspecialty-trained chest radiologist and a third-year radiology resident retrospectively measured maximum diameters of breast tumors on CT images by consensus and compared these with pathologic results. CT determined tumor sizes were also analyzed for concordance with pathologic tumor sizes.

Concordance between CT and pathologic diameters was defined as a tumor size difference of $<5 \mathrm{~mm}$. When a CT measured size was $>5 \mathrm{~mm}$ smaller than pathologic tumor size, CT determined tumor size was considered an underestimation, and conversely, when CT size was $>5 \mathrm{~mm}$ larger than pathologic tumor size, it was considered an overestimation. In addition, concordance rates between IDC and non-IDC patients and between patients with a CT determined tumor diameter of $<20 \mathrm{~mm}$ (Group 1) and $\geq 20 \mathrm{~mm}$ (Group 2) were compared.

\section{Statistical analysis}

Maximum chest CT and pathology determined tumor sizes were compared by linear regression and Spearman's rho correlation analysis. The chi-squared test was used to analyze concordances rates between chest $\mathrm{CT}$ and pathology with respect to tumor size and histologic type. Statistical significance was accepted at the 95\% confidence level $(P<0.05)$. A commercially available software program was used for data processing and analysis (PASW, version 17.0; SPSS, Chicago, IL, USA).

\section{Results}

Overall, longest tumor diameters as determined by chest CT (average, $21 \mathrm{~mm}$, range, 2-74 $\mathrm{mm}$ ) and pathology (average, $22 \mathrm{~mm}$; range, 3-90 $\mathrm{mm}$ ) were not significantly different $(P=0.059)$, and a linear relation was found between the two (pathology determined tumor size $=$
$1.086 \times$ CT determined tumor size -1.141 ; Spearman's rho correlation coefficient, $0.84 ; P<0.001$ ).

Tumor sizes were concordant in 228 of the 285 patients (80\%). However, 36 tumors (12.7\%) were underestimated by CT by an average of $12 \mathrm{~mm}$ (range, $6-36 \mathrm{~mm}$ ) and 21 tumors (7.4\%) were overestimated by an average of $10 \mathrm{~mm}$ (range, 6-19 $\mathrm{mm}$ ). The concordance rate was higher for tumors of $<20 \mathrm{~mm}(88.5 \% \mathrm{vs}$. $71.9 \%$ for tumor size $<20 \mathrm{~mm} v s$. tumor size $\geq 20 \mathrm{~mm}$, $P<0.001)$ and for IDC $(82.4 \% v s .65 .0 \%$ for IDC $v s$. nonIDC, $P=0.011$ ) (Table 2 ).

\section{Discussion}

A number of imaging modalities are used to assess tumor size and extent in breast cancer to determine optimal treatment. Mammography and ultrasonography are the first choices for the screening and diagnosis of breast cancer, but mammography is limited in premenopausal women with dense breasts and ultrasonography is not reliable enough to visualize tumor extensions when tumors exhibit extensive intraductal spread [7]. Breast magnetic resonance imaging (MRI) has attracted much attention recently because its ability to detect breast lesions sufficient to allow the accurate visualization of intraductal lesions around main tumors $[7,8]$. However, although MRI offers the advantage of sensitivity, it tends to overestimate tumor size and is limited by a relatively high false-positive rate, and thus, requires additional biopsies and increases patient anxiety, time, and costs [9-11]. In addition, MRI cannot be performed in patients with claustrophobia and is usually performed in the prone position, whereas surgery is performed with the patient supine. ChestCT examinations, on the other hand, are performed in the supine position, and thus, the positions of breasts in chest CT images better matches the surgical approach. Furthermore, due to the technological improvements offered by MDCT, several authors have concluded that CT of the breast provides an accurate preoperative means of assessing tumor extent and size [8,12-14]. However, breast $\mathrm{CT}$ in these reports had different acquisition technique

Table 2 Comparison of CT and pathologically determined tumor sizes

\begin{tabular}{|c|c|c|c|c|c|c|}
\hline & \multirow[b]{2}{*}{$n(\%)$} & \multicolumn{2}{|c|}{ Size (median \pm SD) } & \multirow[t]{2}{*}{ Concordance with CT (\%) } & \multicolumn{2}{|c|}{ Discordance with CT (\%) } \\
\hline & & $\mathrm{CT}$ & Pathology & & Overestimated by $C T$ & Underestimated by $C T$ \\
\hline Overall & $285(100)$ & $19 \pm 10$ & $20 \pm 13$ & $228(80)$ & $21(7)$ & $36(13)$ \\
\hline \multicolumn{7}{|l|}{$C T$ group $^{a}$} \\
\hline Group 1 (<20 mm) & $139(49)$ & $15 \pm 5$ & $13 \pm 4$ & $123(88)$ & $15(11)$ & $1(1)$ \\
\hline Group 2 ( $\geq 20$ mm) & $146(51)$ & $27 \pm 10$ & $30 \pm 13$ & $105(72)$ & $6(4)$ & $35(24)$ \\
\hline \multicolumn{7}{|l|}{ Tumor type $^{b}$} \\
\hline IDC & $245(86)$ & $20 \pm 10$ & $20 \pm 12$ & $202(83)$ & $18(7)$ & $25(10)$ \\
\hline Non-IDC & 40 (14) & $18 \pm 11$ & $19 \pm 14$ & $26(65)$ & $3(8)$ & $11(28)$ \\
\hline
\end{tabular}

${ }^{a}$ Comparison of group 1 to group 2, $P<0.001$.

${ }^{\mathrm{b}}$ Comparison across tumor types, $P=0.011$. 
with chest $\mathrm{CT}$ and is rarely used in present clinical practice, because the field of view is limited to the breast region and examinations require multiple scans, including precontrast $\mathrm{CT}$ scan and postcontrast $\mathrm{CT}$ scan at 70 to $100 \mathrm{~s}$ after contrast administration $[13,15,16]$, or a dynamic acquisition technique (1, 3, and $8 \mathrm{~min}$ after contrast administration), which inevitably increases radiation dose [17]. In previous studies [17-19], the radiation dose required for breast CT was reported to be 28 $\mathrm{mSv}$, which is approximately 10 times greater than that used for standard mammographic examinations (2.8 $\mathrm{mSv}$ ), and seven times higher than that required for a chest $\mathrm{CT}$ examination.

For the assessment of tumor size in breast cancer, several authors have addressed the accuracies of mammography, ultrasonography (US), and magnetic resonance imaging (MRI) [20-24]; Ramirez et al. [22] concluded that generally, breast mammography determined tumor size correlated better with histopathologic size than MRI or US determined tumor sizes. However, MRI is regarded to be more accurate than mammography or ultrasonography in the ILC subtype, which tends to underestimate the sizes of ILC in up to $70 \%$, and $80 \%$ of cases, respectively $[23,24]$. However, to the best of our knowledge, no previous study has addressed tumor size estimation by chest CT in breast cancer patients.

Because the incidence of metastasis is low and falsepositive findings are more common than true-positive findings [4,5], the current National Comprehensive Cancer Network (NCCN) guidelines do not recommend the routine use of chest $\mathrm{CT}$ in operable breast cancer. Nevertheless, chest CT exanimations are being increasingly used in breast cancer to evaluate pulmonary and hepatic metastases $[5,23,24]$. Somewhat surprisingly, no report has been issued regarding the predictive value of chest CT for the evaluation of tumor size in breast cancer. In the present study, we found a positive correlation between chest CT and pathologically determined tumor sizes and that tumors sizes differed by $<5 \mathrm{~mm}$ in $80 \%$ of our cohort. Furthermore, the concordance rate between $\mathrm{CT}$ and pathologic findings was higher for breast tumors of $<20 \mathrm{~mm}$ and for those of the IDC histologic subtype.

Although current guidelines and available evidence do not support the routine preoperative chest CT evaluation of operable breast cancer, in some patients with a respiratory or abdominal symptom or who deny other imaging modalities, chest $\mathrm{CT}$ could provide an alternative means of evaluating tumor size, especially when the tumor is $<20 \mathrm{~mm}$ of the IDC subtype.

This study had several limitations that warrant consideration. First, it is inherently limited by its retrospective design. In particular, the study is subject to selection bias, because women were selected for chest $\mathrm{CT}$ at the discretion of a breast surgeon, and breast cancers not visualized by chest $\mathrm{CT}$ were not included in the study. Second, we did not compare CT determined tumor sizes with ultrasonography, mammography, or breast MRI determined sizes, because not all patients underwent ultrasonography, mammography, or MRI, and because imagings were performed at different times. A prospective study is required to compare the abilities of chest CT, ultrasonography, mammography, and breast MRI to determine breast cancer size. Third, formalin fixation affects solid tissue measurements. Pritt and colleagues [25] observed $4 \%$ of breast cancer specimens decreased in size after overnight formalin fixation and that $40 \%$ shrank after processing and mounting.

\section{Conclusions}

The present study shows that chest $\mathrm{CT}$ can be used to predict breast tumor size reliably in patients with breast cancer. In fact, chest CT determined breast tumor sizes were found to be well correlated with pathologydetermined sizes, and for most, the size difference was $<5$ $\mathrm{mm}$. In addition, the concordance rate between chest CT and pathology was found to be greater for breast tumors of $<20 \mathrm{~mm}$ and for the IDC subtype.

\section{Abbreviations}

IDC: Invasive ductal carcinoma; ILC: Invasive lobular carcinoma; MDCT: Multidetector computed tomography; MRI: Magnetic resonance imaging; NCCN: National Comprehensive Cancer Network; US: Ultrasonography.

\section{Competing interests}

The authors declare that they have no competing interests. The study had no external funding.

\section{Authors' contributions}

SJA, YSK, and EYK conceived the study and participated in the literature search, writing the manuscript, and editing. In addition, YSK and EYK participated in submission of the manuscript. HKP, EKC, YKK, YMS, and H-YC participated in study design, data analysis, manuscript writing, and editing. All the authors read and approved the final manuscript.

\section{Author details}

'Department of Radiology, Gachon University GilHospital, 1198, Guwol-dong, Namdong-gu, Incheon 405-760, Republic of Korea. ${ }^{2}$ Division of Hematology/ Oncology, Department of Internal Medicine, Gachon University Gil Hospital, Incheon, Republic of Korea. ${ }^{3}$ Department of Surgery, Gachon University Gil Hospital, 1198, Guwol-dong, Namdong-gu, Incheon 405-760, Republic of Korea.

Received: 11 December 2012 Accepted: 17 May 2013 Published: 6 June 2013

\section{References}

1. Jemal A, Siegel R, Xu J, Ward E: Cancer statistics, 2010. CA Cancer J Clin 2010, 60:277-300.

2. Anscher MS, Jones P, Prosnitz LR, Blackstock W, Hebert M, Reddick R, Tucker A, Dodge R, Leight G Jr, Iglehart JD: Local failure and margin status in early-stage breast carcinoma treated with conservation surgery and radiation therapy. Ann Surg 1993, 218:22-28.

3. Fortin A, Larochelle M, Laverdiere J, Lavertu S, Tremblay D: Local failure is responsible for the decrease in survival for patients with breast cancer treated with conservative surgery and postoperative radiotherapy. J ClinOncol 1999, 17:101-109.

4. NCCN practice guidelines in oncology v.2.2011.NCCN; 2011. http://www.ncen. org/professionals/physician_gls/pdf/breast.pdf. 
5. Kim H, Han W, Moon HG, Min J, Ahn SK, Kim TY, Im SA, Oh DY, Han SW, Chie EK, Ha SW, Noh DY: The value of preoperative staging chest computed tomography to detect asymptomatic lung and liver metastasis in patients with primary breast carcinoma. Breast Cancer Res Treat 2011, 126:637-641.

6. Hurwitz LM, Reiman RE, Yoshizumi TT, Goodman PC, Toncheva G, Nguyen G, Lowry C: Radiation dose from contemporary cardiothoracic multidetector CT protocols with an anthropomorphic female phantom: implications for cancer induction. Radiology 2007, 245:742-750.

7. Hata T, Takahashi H, Watanabe K, Takahashi M, Taguchi K, Itoh T, Todo S: Magnetic resonance imaging for preoperative evaluation of breast cancer: a comparative study with mammography and ultrasonography. J Am Collsurg 2004, 198:190-197.

8. Nakahara H, Namba K, Wakamatsu H, Watanabe R, Furusawa H, Shirouzu M, Matsu T, Tanaka C, Akiyama F, Ifuku H, Nakahara M, Tamura S: Extension of breast cancer: comparison of CT and MRI. Radiat Med 2002, 20:17-23.

9. Berg WA, Gutierrez L, NessAiver MS, Carter WB, Bhargavan M, Lewis RS, loffe OB: Diagnostic accuracy of mammography, clinical examination, US, and MR imaging in preoperative assessment of breast cancer. Radiology 2004, 233:830-849.

10. Onesti JK, Mangus BE, Helmer SD, Osland JS: Breast cancer tumor size: correlation between magnetic resonance imaging and pathology measurements. Am J Surg 2008, 196:844-848. discussion 849-850.

11. Vandermeer FQ, Bluemke DA: Breast MRI: state of the art. Cancer Invest 2007, 25:384-392.

12. Uematsu T, Sano M, Homma K: False-positive helical CT findings of multifocal and multicentric breast cancer: is attenuation of tumor useful for diagnosing enhanced lesions? Breast Cancer 2002, 9:62-68.

13. Uematsu T, Sano M, Homma K, Shiina M, Kobayashi S: Three-dimensional helical CT of the breast: accuracy for measuring extent of breast cancer candidates for breast conserving surgery. Breast Cancer Res Treat 2001, 65:249-257.

14. Uematsu TSM, Sano M, Homma K, Sato N: Comparison between high resolution helical CT and pathology in breast examination. Acta Radiol 2002, 43:385-390.

15. Uematsu T, Sano M, Homma K, Makino H, Shiina M, Kobayashi S, Shimizu K: Staging of palpable T1-2 invasive breast cancer with helical CT. Breast Cancer 2001, 8:125-130.

16. Takase K, Furuta A, Harada N, Takahashi T, Igarashi K, Chiba Y, Haga K, Takahashi S: Assessing the extent of breast cancer using multidetector row helical computed tomography. J Comput Assist Tomogr 2006, 30:479-485.

17. Inoue M, Sano T, Watai R, Ashikaga R, Ueda K, Watatani M, Nishimura Y: Dynamic multidetector CT of breast tumors: diagnostic features and comparison with conventional techniques. AJR Am J Roentgenol 2003, 181:679-686.

18. Sardanelli F, Calabrese M, Zandrino F, Melani E, Parodi R, Imperiale A, Massa T, Parodi G, Canavese G: Dynamic helical CT of breast tumors. J Comput Assist Tomogr 1998, 22:398-407.

19. Evans SH, Davis R, Cooke J, Anderson W: A comparison of radiation doses to the breast in computed tomographic chest examinations for two scanning protocols. ClinRadiol 1989, 40:45-46.

20. Behjatnia B, Sim J, Bassett LW, Moatamed NA, Apple SK: Does size matter? Comparison study between MRI, gross, and microscopic tumor sizes in breast cancer in lumpectomy specimens. Int J ClinExpPathol 2010, 3:303-309.

21. Pritt B, Ashikaga T, Oppenheimer RG, Weaver DL: Influence of breast cancer histology on the relationship between ultrasound and pathology tumor size measurements. Mod Pathol 2004, 17:905-910.

22. Ramirez SI, Scholle M, Buckmaster J, Paley RH, Kowdley GC: Breast cancer tumor size assessment with mammography, ultrasonography, and magnetic resonance imaging at a community based multidisciplinary breast center. Am Surg 2012, 78:440-446.
23. March DE, Wechsler RJ, Kurtz AB, Rosenberg AL, Needleman L: CTpathologic correlation of axillary lymph nodes in breast carcinoma. J Comput Assist Tomogr 1991, 15:440-444.

24. Sagel SS: HSL, pleura, chest wall. In Computed body tomography with MRI correlation. Edited by Lee JKT, Sagel SS, Stanley RY. New York, NY: Raven; 2003

25. Pritt B, Tessitore JJ, Weaver DL, Blaszyk $H$ : The effect of tissue fixation and processing on breast cancer size. Hum Pathol 2005, 36:756-760.

doi:10.1186/1477-7819-11-130

Cite this article as: Ahn et al:: The value of chest CT for prediction of breast tumor size: comparison with pathology measurement. World Journal of Surgical Oncology 2013 11:130.

\section{Submit your next manuscript to BioMed Central and take full advantage of:}

- Convenient online submission

- Thorough peer review

- No space constraints or color figure charges

- Immediate publication on acceptance

- Inclusion in PubMed, CAS, Scopus and Google Scholar

- Research which is freely available for redistribution

Submit your manuscript at www.biomedcentral.com/submit
C) Biomed Central 